\title{
Resource Efficient Injection Moulding with Low Environmental Impacts
}

\author{
Gašper Gantar1,* - Andrej Glojek ${ }^{2}$ - Mitja Mori³ - Blaž Nardin ${ }^{4}$ - Mihael Sekavčnik ${ }^{3}$ \\ ${ }^{1}$ ENVITA d.o.o., Slovenia \\ 2 TECOS, Slovenian Tool and Die Development Centre, Slovenia \\ 3 University of Ljubljana, Faculty of Mechanical Engineering, Slovenia \\ ${ }^{4}$ Gorenje toolmaking, Slovenia
}

\begin{abstract}
The selection of most appropriate design and technological solutions to produce certain mould should capture technical performance, economical issues as well as environmental impacts occurred during the mould life cycle. In the paper an approach is presented to support the selection of alternative mould design solutions in the early design stage. It includes the use of Life Cycle Assessment methodology, Life Cycle Cost methodology and is supported by numerical simulations. The approach is applied to a case study where three mould designs for production of the same plastic product were compared. Finally, general conclusions regarding the resource efficient injection moulding processes are presented.
\end{abstract}

Keywords: injection moulding, mould, optimisation, life cycle assessment, life cycle cost analysis

\section{INTRODUCTION}

Injection moulding ranks as one of the most widely used processes for producing plastics products. As in other forming processes, the characteristics of injection moulding procedures and products are significantly affected by the quality of moulds used i.e. tools that are mounted into injection moulding machine to produce repeatable products [1].

Once produced, the moulds are used in production for many years. Since raw materials are becoming scarcer and more expensive, and the costs of energy is also increasing the strategy of mould design should not aim only at cost reduction but also at reducing resource consumption and emissions throughout its entire life cycle.

This paper presents an approach to compare and optimize mould design and production process parameters from technical, economic and also environmental point of view. The results are important for the selection of mould design.

A comparison of life cycle performance of different mould designs is presented on the case study. The environmental impact was quantified by the Life Cycle Assessment (LCA) and the economical by the Life Cycle Cost (LCC) analysis, [2] to [4]. The approach was supported by numerical simulations for the prediction of relevant technical information in the early stage of mould design.

The paper proceeds as follows: Section 1 presents an overview of the case study investigated in the research. Section 2 provides the life cycle model of the mould together with technical background on the injection moulding technology. Section 3 describes the LCA method and compares environmental impacts arising from different mould designs. Section 4 describes LCC analysis for the selection of the best mould design from the economical point of view. Section 5 offers discussion and conclusions.

\section{OVERVIEW OF CASE STUDY}

The case study is presented with three alternative mould designs put side by side. They enable an injection of the same plastic product, shown in Fig. 1, but differ in technical solutions, which contribute to the productivity and resource efficiency during their use phase (injection moulding of plastic products). It is expected that one million products will be produced throughout the mould's life cycle.

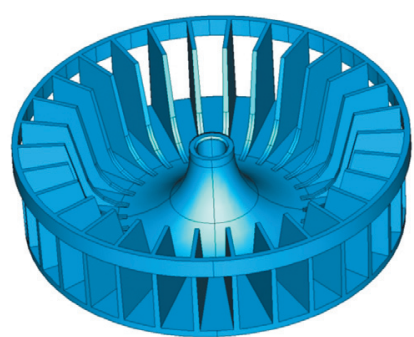

Fig. 1. Studied plastic products produced by mould in the use phase (Material: PP 40\% GF, $d=160 \mathrm{~mm} ; m=137 \mathrm{~g}$; Quantity = 1 mio parts)

Three mould designs, which were considered as appropriate by the mould designer, are presented and described in Fig. 2. 


\section{LIFE CYCLE OF A MOULD}

Life cycle of a mould is presented in Fig 3. Two main stages i.e. mould manufacturing and the use of the mould (injection moulding), are described in details in the following sub- chapters.

It is assumed in our case study that mould components will not be reused in similar moulds in the future; although in general some mould components i.e. guides can be reused.

\subsection{Mould Production}

For smaller moulds, such as the one investigated in the case study, the main standard metal elements are sawed to rough shape from rolled slabs and bars which are then milled, turned and grinded to final tolerance geometry.
Mould components like plates, injectors, ejectors, guiding elements and others are commercially available as standard elements.

The patterns which form the final product geometry within standard plates (sometimes also called active mould surfaces) are usually produced by CNC milling and/or Electric Discharge Machining (EDM). In our case only the CNC milling process was used. The heat treatment was used to improve the quality of active mould parts.

CNC milling of tool steels requires cutting tools that are strong, precise and expensive, involving special steels and ceramics that are usually coated to improve wear characteristics and it also requires other auxiliary materials; such as cutting fluids.

The main design parameters of the mould which influence properties of the production process and the

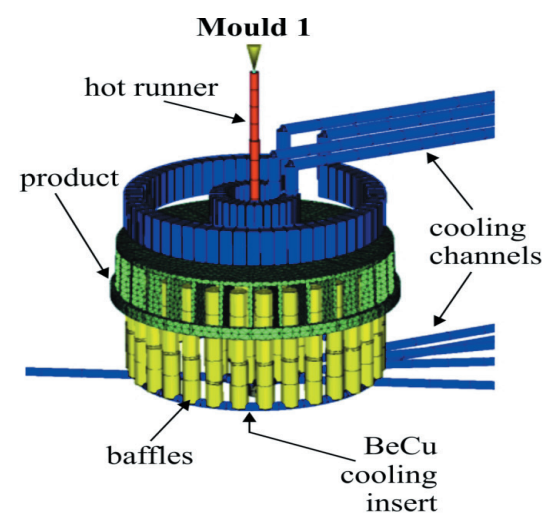

\section{DESCRIPTION}

An Integrated hot and cold runner injection system is used. The consumption of plastic material during injection moulding is low since only minimal cold runner has to be removed from the product after the injection moulding. The ejection of small cold runner is difficult; therefore a slightly higher reject rate is expected compared to cold runner system. The hot runner system consumes additional electrical energy during the injection moulding process. The conventional cooling system with circular cooling was used. Due to the shape of injection system it was not possible to implement bubler at the ejection side to cool the critical inner side of the plastic product; therefore cycle times are high. Additional BeCu cooling insert was implemented to improve the cooling of the moulds and to subsequently reduce the cycle times.

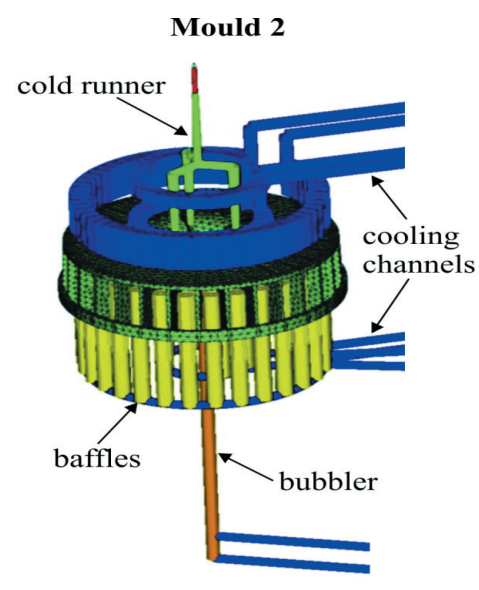

\section{DESCRIPTION}

The cold runner injection system with three injection points is used. If optimized, such injection system enables a very stable production (low reject rate). The consumption of plastic material during injection moulding is high since cold runner has to be removed from the product after the injection moulding. For the production of injection system an additional steel plate is needed, so more material is used for the production of the mould. The conventional cooling system with circular cooling is used, which enables acceptable cycle times.

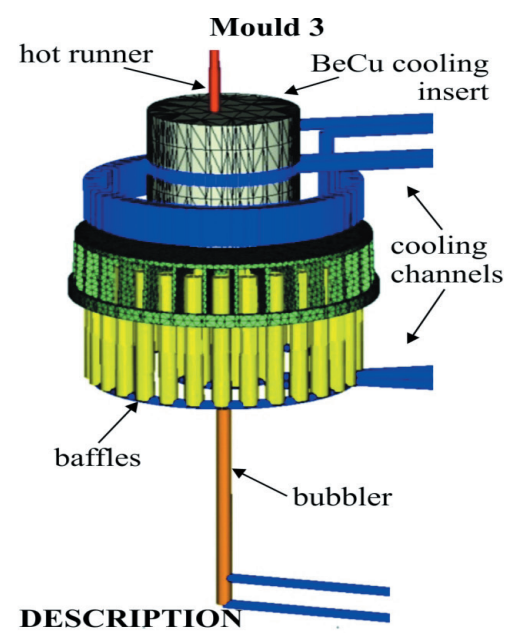

The hot runner injection system is used. The consumption of plastic material during the injection moulding is minimal since there is no cold runner that needs to be removed from the product after the injection moulding. The injection point of the hot runner system cannot be placed at the centre of the part therefore additional problems with achieving the roundness of the product are expected and subsequently a higher reject rate. The hot runner system consumes additional electrical energy during injection moulding process. A conventional tempering system with circular cooling was used. An additional BeCu cooling insert was implemented into mould design at injection side to improve the heat transfer and subsequently reduce the cycle times.

Fig. 2. Alternative mould designs 


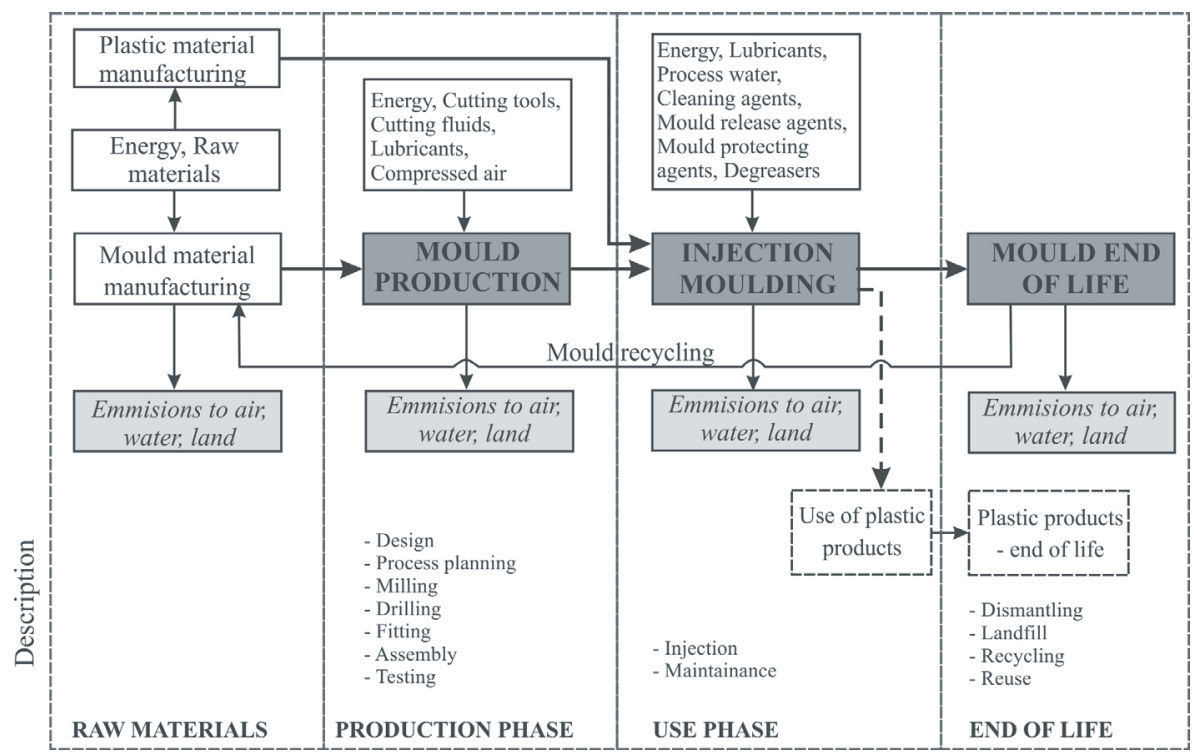

Fig. 3. LCA model of a mould life cycle

product are the injection system (runners), and the cooling system.

\subsection{Injection Moulding Process}

The injection moulding process begins by feeding the plastic material and appropriate additives from the hopper to the heating/injection cylinder of the injection moulding machine.

The process consumes a great amount of electric energy and generates environmental emissions. Various kinds of chemicals are used both in the protection of moulds and during the injection moulding process. These chemicals are: lubricants, cleaning agents, mould release agents, mould protecting agents and degreasers. Most of the chemicals are packaged in high-pressure containers and applied as atomized spray. The ingredients are mainly petroleum or hydrocarbon by-products (i.e. paraffinic oil, propane and isobutane). If the training of workers is appropriate, the emissions from these chemicals are not substantial.

Minor amounts of particulates come from the polymer feed and mixing in the hopper as well as trimming of the products and grinding of runners and other scrap. Minor amounts of volatile emissions are released from vents in the heating/injection cylinders and the moulds. These emissions consist of traces of monomers, additives and decomposition products of polymers. Decomposition products occur when the processing temperature reaches the temperature where the polymer begins to decompose, which rarely happens in serial production of polypropylene (PP) products.

The main injection moulding parameters that influence the environmental impact of the production process are: cycle time, mould temperature, clamping force, profile of packing pressure and properties of machine.

\section{LIFE CYCLE ASSESMENT (LCA)}

The most suitable method for evaluating the environmental impact of the product in its entire life cycle is the LCA. The LCA means compiling and evaluation of inputs and outputs and potential environmental impacts of a product system during its lifetime.

The LCA method consists of four stages: definition of the goal and scope, construction of the product's life cycle model with all mass and energy flows; the so called "Life Cycle Inventory Analysis", evaluation of the environmental relevance of all flows; the so called "Life Cycle Impact Assessment" and finally, the interpretation of the results.

\subsection{Goal and Scope Definition}

The goal was the assessment of the environmental impact of three alternative mould designs, previously defined and described in Fig. 2. The moulds have different design solutions and are made from different materials and they also differ in their characteristics during the use phase. Therefore, different 
environmental impacts are expected throughout their life cycles.

\subsubsection{Functional Unit}

A functional unit is the production of one million plastic products, presented in Fig. 1.

\subsubsection{Study Boundaries and Simplifications}

This study includes cradle-to-grave environmental impacts of producing and using an injection mould for production of one million plastic parts, presented in Fig. 1. The system boundaries include: the cradle-togate material and environmental impacts of the energy used, the production of moulds, the use of moulds and disposal of moulds at the end of life cycle. The models include impacts associated with the upstream production of all materials and energy used and endof-life treatment for all materials.

Since the aim of the study is a comparison of mould designs, the use of plastic products was considered out of scope. This means that the flow of plastic material that enters the system and leaves it in the form of a product is not included into the model. The plastic material of rejected parts and runners are taken into consideration since for the production of the studied products presented in Fig. 1 it was not allowed to grind and reuse the rejected parts and runners. The human labour was also not included into the study.

The retail, internal and external transport are excluded from the study (transport distances of moulds are minimal and transport distances for plastic materials are not known). The production of infrastructure (buildings, machinery, etc.) and maintenance of infrastructure (e.g. replacement of hydraulic oil in machines) are also excluded from the study.

In the first analysis it was assumed that the runners and rejected parts were incinerated. The mould materials were recycled at the end of mould life.

Due to the absence of more accurate data, the following simplifications were also used:

- For the materials of moulds and cutting tools, used for CNC machining, we took from the LCA database in $\mathrm{GaBi}$ [4] the material with most similar chemical structure to that of the actual materials.

- For all standard elements used in mould production (base plates, injectors, ejectors, guiding elements and other available standard elements) only the environmental impact from the acquisition of materials was considered but the environmental impact caused by production of standard mould components was neglected.

- The environmental emissions associated with the production and uses of auxiliary materials mentioned in Chapter 2.2 were neglected as well.

- Cutting fluids were modelled as a mixture of lubricant and process water.

- $\mathrm{BeCu}$ material is modelled as a combination of 50\% Copper, 15\% Aluminium and 5\% Steel.

- It is estimated that the environmental impact of the maintenance level of all mould design solutions is the same and low (mainly manual work is included, which is excluded from our study), therefore it was neglected.

Table 1. Major resource and energy consumption over the mould life cycle

\begin{tabular}{|c|c|c|c|}
\hline & Mould 1 & Mould 2 & Mould 3 \\
\hline \multicolumn{4}{|l|}{ Materials for mould } \\
\hline Steel $[\mathrm{kg}]$ & 320 & 340 & 320 \\
\hline $\mathrm{BeCu}[\mathrm{kg}]$ & 3 & 0 & 15 \\
\hline \multicolumn{4}{|l|}{ Mould production } \\
\hline Design [hours] & 120 & 120 & 120 \\
\hline Process planning [hour] & 75 & 80 & 78 \\
\hline $\begin{array}{ll}\text { CNC milling } & \text { Setup [hour] } \\
& \text { Machining [hour] }\end{array}$ & $\begin{array}{c}2 \\
75\end{array}$ & $\begin{array}{c}2 \\
80\end{array}$ & $\begin{array}{c}2 \\
78 \\
78\end{array}$ \\
\hline $\begin{array}{ll}\text { CNC drilling } & \text { Setup [hour] } \\
& \text { Machining [hour] }\end{array}$ & $\begin{array}{c}2 \\
36 \\
\end{array}$ & $\begin{array}{c}2 \\
38 \\
\end{array}$ & $\begin{array}{c}2 \\
36 \\
\end{array}$ \\
\hline $\begin{array}{l}\text { Components fitting and polishing } \\
\text { - mainly manual labour [hour] }\end{array}$ & 118 & 120 & 115 \\
\hline $\begin{array}{l}\text { Assembly - mainly manual labour } \\
\text { [hour] }\end{array}$ & 28 & 30 & 28 \\
\hline $\begin{array}{l}\text { Final testing at injection moulding } \\
\text { machine [hour] }\end{array}$ & 8 & 8 & 8 \\
\hline $\begin{array}{l}\text { Compresses air consumption } \\
{\left[\mathrm{Nm}^{3}\right]}\end{array}$ & 0.5 & 0.5 & 0.5 \\
\hline Energy consumption [kWh] & 2900 & 3000 & 2900 \\
\hline \multicolumn{4}{|l|}{ Injection moulding } \\
\hline Injection cooling time [s] & 39 & 34 & 35,5 \\
\hline Injection cycle time $[\mathrm{s}]$ & 58 & 54 & 54,5 \\
\hline Clamping force $\left[10^{3} \mathrm{~kg}\right]$ & 90 & 90 & 90 \\
\hline Plastic material consumption [g] & 137.4 & 143.9 & 137.0 \\
\hline Expected reject rate [\%] & 0.5 & 0.4 & 2 \\
\hline $\begin{array}{l}\text { Energy consumption for injection } \\
\text { moulding }[\mathrm{kWh} / \mathrm{part}]\end{array}$ & 0,138 & 0,134 & 0,137 \\
\hline $\begin{array}{l}\text { Energy consumption for grinding } \\
\text { of runners and reject [kWh/kg] }\end{array}$ & 0.025 & 0.025 & 0.025 \\
\hline
\end{tabular}

\subsection{Inventory Analysis}

The production system is the same for all the three studied mould alternatives - Engel injection moulding machine with $900 \mathrm{kN}$ clamping force and peripheral 
devices. The major resources and energy consumption throughout the mould life cycle are presented in the Table 1.

\subsubsection{Data Collection}

The consumption of material and time for mould production was estimated by industrial experts based on CAD moulds' models.

The injection cooling times and the amount of plastic material consumed (for part and runners) were predicted by numerical simulations (NS). NS is the most reliable method for predicting relevant technical information of the studied solutions in the early design phase. In our study the full 3D analyses (flow, cool and wrap) with MoldFlow software were used for prediction of output production process parameters based on different input mould design solutions [5].

The total cycle times were estimated based on measurements performed in the industrial environment and suggestions from literature [6].

Consumption of electrical energy during injection mould production phase and the use of the mould were estimated by measurements performed in the

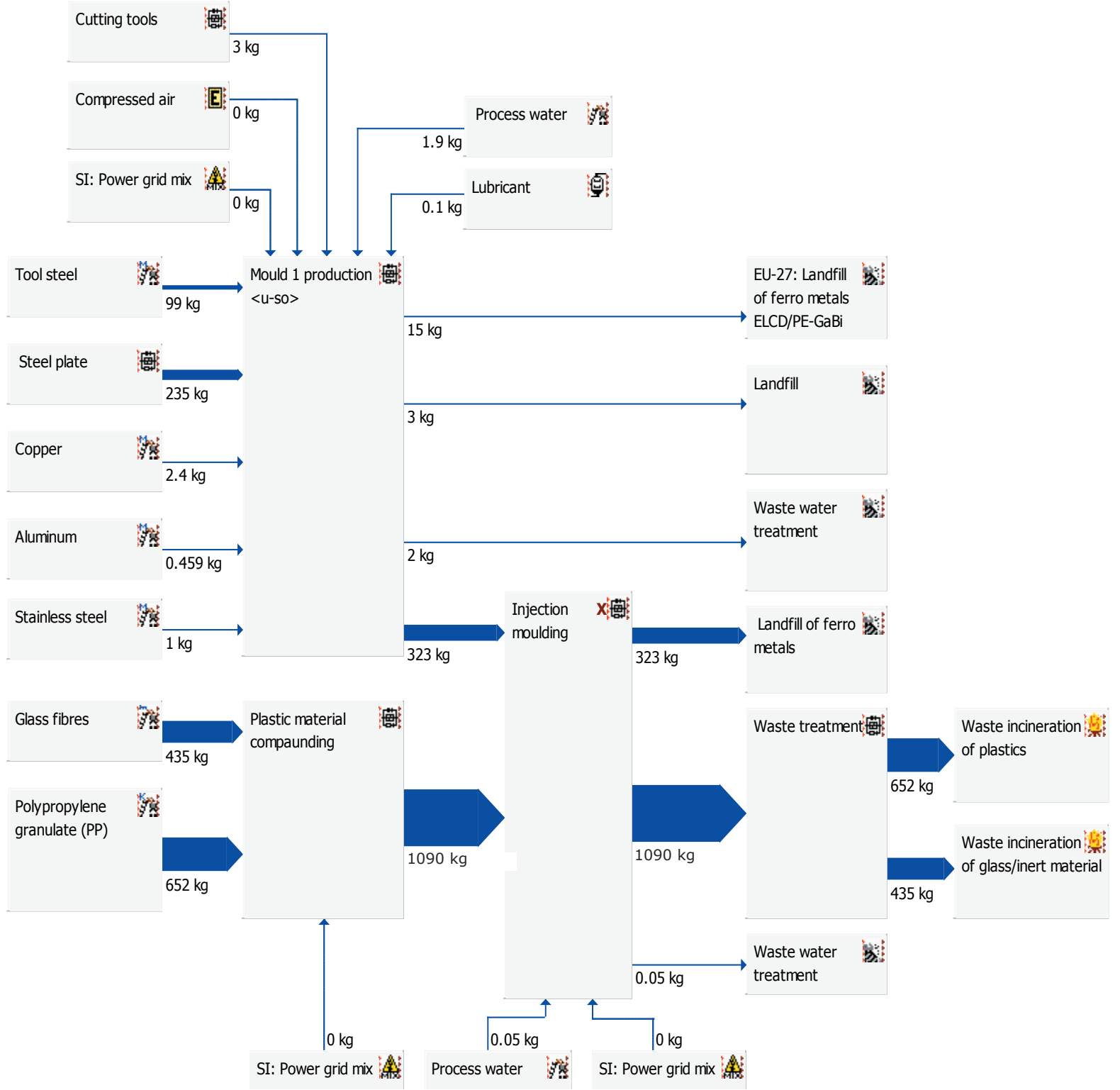

Fig. 4. LCA model from GaBi software 
industrial environment and suggestions from literature [6]. The potential of different moulds designs to reduce energy consumption during use phase was estimated on the basis of cooling time calculation by FEM and data from literature regarding energy consumption during injection moulding [7] stating that about 50\% of energy consumption in a typical injection moulding cycle is required for plasticizing and the rest can be reduced by shortening of the cycle time.

Consumption of compressed air was evaluated indirectly according to measurements of consumption of the entire production facility.

\subsection{Impact Assessment}

The LCA model was created using the GaBi software system for life cycle engineering, developed by PE International $\mathrm{GmbH}$ [8]. The model is presented in Fig. 4

The impact assessment of all inputs and outputs was performed using the Eco-indicator 99 (EI'99), which consist of several environmental impact categories, aggregating all emissions and resources consumption into three areas: Human Health (HH), Ecosystem Quality (EQ) and Resources (R). Afterwards, the methodology weights the scores into a single value. The weighting coefficients were applied according to the hierarchic/average perspective (H/A). The EI'99 was also used by other authors studying the environmental impact of moulds, therefore it was selected owing to a simple comparison of results [9].

\subsection{Interpretation of Results}

Table 2. Environmental impact of the alternative mould design solutions (El'99 points)

\begin{tabular}{lccc}
\hline & Mould 1 & Mould 2 & Mould 3 \\
\hline $\begin{array}{l}\text { Environmental impact } \\
\text { (El'99 points) }\end{array}$ & 4556 & 6031 & 4972 \\
\hline Mould end of life & 4 & 4 & 4 \\
\hline Mould material and production & 108 & 110 & 115 \\
\hline Plastic material production* ${ }^{* *}$ & 241 & 1637 & 608 \\
\hline Injection moulding process & 4203 & 4280 & 4245 \\
\hline * If runners and rejected parts are not granulated and reused. \\
** Only the material that is disposed in the form of runners and \\
rejected parts was included into the calculation (material included \\
into products that leave the production facility was not included for \\
greater transparency).
\end{tabular}

The EI'99 score obtained for the production of 1 mio parts (Fig. 5, Table 2) shows that the major environmental impact is caused during the injection moulding mainly due to energy consumption of the injection moulding machine. The production of the mould and its end of life only has a minor environmental impact. It is shown that the design solution 1 is the most effective from the environmental point of view.

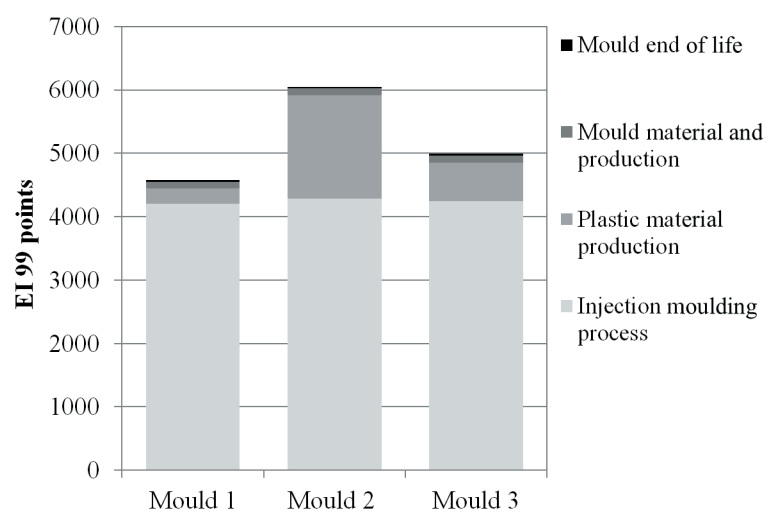

Fig. 5. Environmental impact of the alternative mould design solutions (El'99 points)

\section{LIFE CYCLE COST}

The LCC generally refers to all the foreseen costs associated with the product throughout its life from "cradle to grave". The LCC is an estimate of total costs from inception to disposal for both equipment and projects related to the products life cycle. The objective of LCC analysis is to choose an alternative where the lowest possible long term costs of ownership are achieved, [2] and [4].

As with the calculations of the environmental impacts, technological characteristics of the mould considerably influence the use-phase (maintenance level and characteristics of injection moulding process such as cycle time, amount of material wasted, reject rate, closing pressure, required temperature of plastic material, etc.).

The data about all the relevant production steps for mould production, the material consumed, the labour involved, equipment used, cutting tools used and other consumables enable the estimation of the costs of the mould. The comparison of mould designs should also include the subsequent mould life phases like injection moulding together with mould maintenance and mould end of life scenario (see Fig. 3 ). The most relevant inputs required to perform the LCC analysis are presented in Tables 1 and 3.

Some simplifications were assumed. The operator's and engineer's wages, energy costs, consumables and material costs, annual available production time of equipment are kept constant for all mould design solutions. The calculation was done with the assumption that the runners are not reused. 
Table 3. Cost input values

\begin{tabular}{|c|c|c|c|c|}
\hline \multirow{2}{*}{\multicolumn{2}{|c|}{ Costs of standard components [€] }} & Mould 1 & Mould 2 & Mould 3 \\
\hline & & 5000 & 4500 & 5000 \\
\hline \multicolumn{2}{|c|}{ Costs of disposable cutting tools [€] } & 700 & 600 & 700 \\
\hline \multicolumn{2}{|c|}{ Costs of other consumables [€] } & 100 & 100 & 100 \\
\hline \multicolumn{4}{|c|}{$\begin{array}{l}\text { Costs of items for all mould designs on functional unit / } \\
\text { general data }\end{array}$} & Cost \\
\hline \multicolumn{5}{|c|}{ Materials* } \\
\hline \multicolumn{4}{|c|}{ Tool steel $[€ / \mathrm{kg}]$} & 7.8 \\
\hline \multicolumn{4}{|c|}{$\mathrm{BeCu}[€ / \mathrm{kg}]$} & 11.5 \\
\hline \multicolumn{5}{|c|}{ Employees } \\
\hline \multicolumn{4}{|c|}{ Engineer wage [€/hour] } & 20 \\
\hline \multicolumn{4}{|c|}{ Operator wage [€/hour] } & 12 \\
\hline \multicolumn{5}{|c|}{ Machines - process costs ${ }^{\star \star},{ }^{\star \star \star}$} \\
\hline \multicolumn{4}{|c|}{ HSM - CNC milling machine [€/hour] } & 40 \\
\hline \multicolumn{4}{|c|}{ CNC drilling machine [€/hour] } & 22 \\
\hline \multicolumn{4}{|c|}{ Injection moulding machine [€/hour] } & 17 \\
\hline \multicolumn{4}{|c|}{ Electricity $[€ / \mathrm{kWh}]$} & 0.1 \\
\hline \multicolumn{5}{|c|}{ Injection moulding general data } \\
\hline \multicolumn{4}{|c|}{ Plastic material $[€ / \mathrm{kg}]$} & 1.7 \\
\hline \multicolumn{4}{|c|}{ Setup time of injection moulding machine [hour] } & 3 \\
\hline \multicolumn{4}{|c|}{ Batch size during injection moulding [part] } & 16000 \\
\hline \multicolumn{5}{|c|}{ 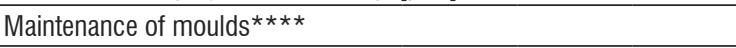 } \\
\hline \multicolumn{4}{|c|}{ Basic cleaning [€/year] } & 150 \\
\hline \multicolumn{4}{|c|}{ Adjustment of the splitting line [€/year] } & 1070 \\
\hline \multicolumn{4}{|c|}{ Adjustment of ejectors [€/year] } & 600 \\
\hline \multicolumn{4}{|c|}{ Lubrication of guiding system [€/year] } & 60 \\
\hline \multicolumn{4}{|c|}{ Polishing [€/year] } & 120 \\
\hline \multicolumn{4}{|c|}{ Hot runner repair [€/year] } & 540 \\
\hline \multicolumn{4}{|c|}{ Average cost of materials for non-standard compor } & ents only. \\
\hline ** & \multirow{2}{*}{\multicolumn{4}{|c|}{$\begin{array}{l}\text { The input values are average values gathered from practice. } \\
\text { Process costs include machine and labour (operator of the } \\
\text { machine is included). }\end{array}$}} \\
\hline *** & & & & \\
\hline$\star \star \star \star *$ & The mould will be in use for 3 & 2 years. & & \\
\hline
\end{tabular}

Table 4. LCC results

\begin{tabular}{lccc}
\hline & Mould 1 & Mould 2 & Mould 3 \\
\hline Total costs [€] & 570427 & 558742 & 560108 \\
\hline Costs of the mould [€] & 18446 & 18369 & 18728 \\
\hline Plastic material production [€] & 234748 & 245438 & 237558 \\
\hline Injection moulding [€] & 306015 & 285448 & 292604 \\
\hline Maintenance costs [€] & 11218 & 9487 & 11218 \\
\hline End of life costs [€] & 0 & 0 & 0 \\
\hline Costs per part [€] & 0.570 & 0.559 & 0.560 \\
\hline
\end{tabular}

LCC was used to compare economic viability of alternative mould design solutions. The results are presented in Table 4. It is shown that design solutions 2 and 3 are more viable from the economical point of view. Taking into account that the runners and rejected parts can be ground and reused with minimal additional processing costs; the design solution 2 is also promising.

\section{RESULTS AND CONCLUSIONS}

This paper presents an approach to compare and optimize mould design and production process parameters from technical, economic and also environmental point of view. The results are important for the choice of mould design and also for further optimisation.

\subsection{Comparison and Ranking of Mould Designs}

The mould designs can be compared if the most important results from the previous sections of the paper are presented in one table (see Table 5).

Table 5. Comparison of mould designs

\begin{tabular}{lccc}
\hline & Mould 1 & Mould 2 & Mould 3 \\
\hline \multirow{2}{*}{ Costs of the mould [€] } & $2^{\text {nd }}$ & 1 st & $3^{\text {rd }}$ \\
& 18445 & 18369 & 18727 \\
\hline \multirow{2}{*}{ LCC $[€]$} & $3^{\text {rd }}$ & 1 st & $2^{\text {nd }}$ \\
& 570427 & 558742 & 560108 \\
\hline Environmental impact & 1 st & 3 rd & $2^{\text {nd }}$ \\
(El'99 points) & 4556 & 6031 & 4972 \\
\hline
\end{tabular}

The costs of mould design 2 are the lowest, and also the total costs during entire life cycle are the lowest for mould design 2 . On the contrary the mould design 1 , which is not outstanding regarding costs, enables production with the lowest environmental impact.

\subsubsection{Optimisation of Mould and Production Process}

The efficient optimisation of the process from the environmental aspect can also be performed based on results from Table 2. As we have seen from the analysis, the two main causes of the environmental burden during the production of plastic products are:

- electric energy consumed during injection moulding process;

- environmental impact caused by production and disposal of plastic material that finishes in the form of waste runners or rejected products.

Since the available machinery for injection moulding in the company was limited, the replacement of the hydraulic Engel injection moulding machine with an energy efficient one was not possible.

For the production of the studied products presented in Fig. 1 it was not allowed to grind and reuse the rejected parts and runners. But the 
company found the possibility of using the rejected material $\mathrm{PP}+40 \% \mathrm{GF}$ for another product with lower requirements (inner plastic parts will low load carrying requirements). The company introduced the grinder into the production process. Additional electric energy is used for grinding the runners and the reject parts, but the benefit is the reduced amount of material needed for production of other products. It was calculated with the modified LCA models that by using this solution in combination with mould design 2 (which is most cost effective), the company could achieve only a minimal reduction of costs (total costs per part are reduced by $1.25 \%$ ) but a significant reduction of the environmental impact (the total environmental impact can be reduced by approximately $20 \%$; the exact value depends on further reuse of rejected material and allocation procedure used in LCA calculations). On the contrary changes in mould design that do not affect its performance during injection moulding or improvement of the end of life strategy cannot reduce the total environmental burden significantly.

In general, the following conclusions can be derived from the study:

- the potential of the mould design to influence the environmental impact of the injection moulding phase is high,

- in mass production, better production process usually consumes fewer resources (energy and material),

- the presented methodology provides manufacturing companies with feasible means to assess their environmental performance.

In the paper, it is assumed the injected parts produced comply with the confirmed quality in all three mould solutions. In case where technical performance (reliability of technology, time-toplastic parts, number of production steps, etc.) would be considerably different, it is reasonable to include technical performance into the decision-making system.

Finally, it should be noted that the presented approach can be incorporated into the standard service of the advanced mould manufacturing companies.

\section{ACKNOWLEDGEMENT}

To company Daplast for supplying the relevant industrial data. The presented research work was cofinanced by European Social Fund within the project No. JR-2-2009 (150/2010) at national agency JAPTI. Their contribution is greatly acknowledged.

\section{REFERENCES}

[1] Tang, S.H., Kong, Y.M., Sapuan, S.M., Samin, R., Sulaiman, S. (2006). Design and thermal analysis of plastic injection mould. Journal of Materials Processing Technology, vol. 171, no. 2, p. 259-267, DOI:10.1016/j.jmatprotec.2005.06.075.

[2] Horne, R., Grant, T., Verghese, K. (2009). Life Cycle Assessment: Principles, Practice and Prospects, CSIRO Publishing, Collingwood.

[3] Folgado, R., Pecas, P., Henriques, E. (2010). Life cycle cost for technology selection: A Case study in the manufacturing of injection moulds. International Journal of Production Economics, vol. 128, p. 368-378, DOI:10.1016/j.ijpe.2010.07.036.

[4] Dhillon, B.S. (2010). Life Cycle Costing for Engineers, 1 st ed., CRC Press, Taylor and Francis Group, Boca Raton.

[5] Autodesk Simulation Moldflow Insight (2012). Autodesk Simulation Moldflow plastic injection molding simulation software, Autodesk, San Rafael.

[6] Lucchetta, G., Bariani, P.F. (2010). Sustainable design of injection moulded parts by material intensity reduction. CIRP Annals - Manufacturing Technology, vol. 59 , p. 33-36, DOI:10.1016/j.cirp.2010.03.092.

[7] Morrow, W.R., Qi, H., Kim, I., Mazumder, J., Skerlos, S.J. (2007). Environmental aspect of laserbased and conventional tool and die manufacturing. Journal of Cleaner Production, vol. 15, p. 923-943, DOI:10.1016/j.jclepro.2005.11.030.

[8] PE International: Software and Database for Life Cycle Engineering (2010). Leinfelden-Echterdingen.

[9] Pecas, P., Ribeiro, I., Folgado, R., Henriques, E. (2009). A life cycle engineering model for technology selection: a case study on plastic injection moulds for low production volume. Journal of Cleaner Production, vol. 17, p. 846-856, DOI:10.1016/j. jclepro.2009.01.001. 